\title{
CUSTOS DE PRODUÇÃO E LUCRATIVIDADE DE CULTIVARES DE MAMONA EM DIFERENTES ARRANJOS DE PLANTAS ${ }^{1}$
}

\author{
Ricardo Alessandro Petinari ${ }^{2}$, Rogério Peres Soratto ${ }^{3}$, \\ Genivaldo David de Souza-Schlick ${ }^{3}$, Maurício Dutra Zanotto ${ }^{3}$, Sônia Maria Pessoa Pereira Bergamasco²
}

\section{ABSTRACT \\ PRODUCTION COSTS AND PROFITABILITY OF CASTOR BEAN CULTIVARS UNDER DIFFERENT PLANT ARRANGEMENTS}

The optimal combination between row spacing and plant population can lead to the economic maximization of castor bean yield. This study aimed to analyze the production cost and profitability per hectare of two castor bean cultivars (IAC 2028 and FCA-PB), under eight different plant arrangements, in the summer of 2007/2008 and 2008/2009, in Botucatu, São Paulo State, Brazil. The best economic results were obtained when using narrower row spacing $(0.45 \mathrm{~m})$. The highest production cost occurred in $2007 / 2008$, for the 70,000 plants ha $^{-1}$ population, due to the use of a higher amount of seeds and fungicide applications, when compared to 2008/2009. The FCA-PB cultivar showed the highest profitability index $(27.46 \%)$, with the combination of $0.45 \mathrm{~m}$ row spacing and 55,000 plants ha- ${ }^{-1}$, in 2007/2008, with operational profit of US\$ $655.47 \mathrm{ha}^{-1}$.

KEY-WORDS: Ricinus communis L.; economic analysis; plant population.

\section{INTRODUÇÃO}

A demanda industrial por óleos vegetais cresce a cada ano e o interesse mundial por oleoquímicos está em alta, haja vista a sua diversificada forma de aplicação. A mamoneira (Ricinus communis L.) é um arbusto de cujo fruto se extrai um óleo de excelentes propriedades, de largo uso como insumo industrial, devido ao fato de que, em muitas de suas aplicações, não se pode substituí-lo por outros óleos vegetais (Santos et al. 2007). Além disto, o óleo de mamona é, também, opção para a produção de biocombustível (Nass et al. 2007).

\section{RESUMO}

A combinação ótima de espaçamento entre fileiras e populações de plantas pode levar à maximização econômica da produção da cultura da mamona. Este trabalho objetivou analisar o custo de produção e a lucratividade por hectare de duas cultivares de mamona (IAC 2028 e FCA-PB), em oito diferentes arranjos de plantas, na safra de verão dos anos agrícolas 2007/2008 e 2008/2009, em Botucatu (SP). Os melhores resultados econômicos foram obtidos quando se utilizou espaçamento entre fileiras mais estreito $(0,45 \mathrm{~m})$. O maior custo de produção ocorreu em 2007/2008, para a população de 70.000 plantas ha-1 devido à utilização de maior quantidade de sementes e aplicações de fungicidas, em relação a 2008/2009. A cultivar FCA-PB apresentou o melhor índice de lucratividade $(27,46 \%)$, obtido com a utilização da combinação do espaçamento entre fileiras de $0,45 \mathrm{~m}$ e 55.000 plantas ha $^{-1}$, no ano agrícola 2007/2008, com lucro operacional de $\mathrm{R} \$ 1.147,08 \mathrm{ha}^{-1}$.

PALAVRAS-CHAVE: Ricinus communis L.; análise econômica; população de plantas.

O Brasil já ocupou lugar de destaque na produção mundial de mamona (Santos et al. 2007). Segundo a FAO (2008), em 2008, destacavam-se, na produção mundial, a Índia (1.123.000 t), a China (220.000 t) e o Brasil (120.449 t).

Em 2008, de acordo com dados do IBGE (2010), a Bahia se destacou como o principal Estado produtor, seguido por Minas Gerais, Ceará, Pernambuco e São Paulo. A estimativa de produtividade média no Brasil, para a safra 2010/2011, foi de $675 \mathrm{~kg} \mathrm{ha}^{-1}$ (Conab 2010), nível de produção considerado muito baixo (Santos et al. 2007). Isto se explica em razão de os produtores brasileiros não utilizarem melhores níveis tecnológicos, principalmente em ter-

1. Trabalho recebido em maio/2011 e aceito para publicação em abr./2012 (nº registro: PAT 14379).

2. Universidade Estadual de Campinas (Unicamp), Faculdade de Engenharia Agrícola, Campinas, SP, Brasil. E-mails: ricardopetinari@ig.com.br, sonia@feagri.unicamp.br.

3. Universidade Estadual Paulista (Unesp), Faculdade de Ciências Agronômicas, Departamento de Produção Vegetal, Botucatu, SP, Brasil.E-mails: soratto@fca.unesp.br, zanotto@fca.unesp.br, genivald@fca.unesp.br. 
mos de uso de insumos industriais como fertilizantes, sementes melhoradas, ou mesmo melhores sistemas de cultivo, semeadura e colheita (Savy Filho et al. 1999). Contudo, segundo Savy Filho \& Banzatto (1990), lavouras tecnificadas podem alcançar produtividades de $1.500 \mathrm{~kg} \mathrm{ha}^{-1}$ a $4.000 \mathrm{~kg} \mathrm{ha}^{-1}$.

Dentre as técnicas culturais que afetam a produtividade da oleaginosa estão o espaçamento entre fileiras e a população de plantas (Severino et al. 2006a e 2006b, Carvalho et al. 2010).

Um número de plantas abaixo do ideal pode favorecer o desenvolvimento de plantas daninhas, aumentando, assim, os custos com o controle das mesmas, enquanto o aumento da população de plantas provoca competição por nutrientes, água, luz e $\mathrm{CO}_{2}$, resultando em decréscimo de produção por planta e até redução da produtividade por área. A combinação ótima de espaçamento entre fileiras e densidade de plantas na fileira, para uma cultura, é uma das tecnologias de maior simplicidade de aplicação e que leva à maximização econômica da produção.

Assim, o presente trabalho objetivou avaliar os custos e a lucratividade da produção de duas cultivares de mamona (IAC 2028 e FCA-PB), em dois espaçamentos entre fileiras e diferentes populações de plantas, em dois anos agrícolas.

\section{MATERIAL E MÉTODOS}

O presente estudo foi conduzido no município de Botucatu (SP) (48 $23^{\circ}$ 'W, $22^{\circ} 58^{\prime}$ 'S e $740 \mathrm{~m}$ de altitude), na safra de verão dos anos agrícolas 2007/2008 e 2008/2009. O clima é do tipo Cwa (Köppen), que se caracteriza como tropical de altitude, com inverno seco e verão quente e chuvoso. O solo da área experimental classifica-se como Latossolo Vermelho distroférrico (Embrapa 2006).

Antes da instalação do experimento, em cada ano agrícola, foram coletadas amostras de solo, à profundidade de 0-0,20 m, para caracterização química (Raij et al. 2001). Em 2007/2008, os resultados foram: matéria orgânica $=36 \mathrm{~g} \mathrm{dm}^{-3} ; \mathrm{pH}\left(\mathrm{CaCl}_{2}\right)=$ 5,3; P (resina) $=37 \mathrm{mg} \mathrm{dm}^{-3} ; \mathrm{K}=2,8 \mathrm{mmol}_{\mathrm{c}} \mathrm{dm}^{-3}$; $\mathrm{Ca}=41 \mathrm{mmol}_{\mathrm{c}} \mathrm{dm}^{-3} ; \mathrm{Mg}=15 \mathrm{mmol} \mathrm{dm}^{-3} ; \mathrm{CTC}=$ $104,8 \mathrm{mmol}_{\mathrm{c}} \mathrm{dm}^{-3}$; e saturação por bases $=56 \%$. $\mathrm{Na}$ área utilizada em $2008 / 2009$, os resultados foram: matéria orgânica $=38 \mathrm{~g} \mathrm{dm}^{-3} ; \mathrm{pH}\left(\mathrm{CaCl}_{2}\right)=$ 4,3; $\mathrm{P}$ (resina) $=26 \mathrm{mg} \mathrm{dm}^{-3} ; \mathrm{K}=3,3 \mathrm{mmol}_{\mathrm{c}} \mathrm{dm}^{-3}$; $\mathrm{Ca}=36 \mathrm{mmol}_{\mathrm{c}} \mathrm{dm}^{-3} ; \mathrm{Mg}=15 \mathrm{mmol}_{\mathrm{c}} \mathrm{dm}^{-3} ; \mathrm{CTC}=$ $121,3 \mathrm{mmol}_{\mathrm{c}} \mathrm{dm}^{-3}$; e saturação por bases $=45 \%$.
O experimento de campo foi conduzido em blocos casualizados, com quatro repetições. Para cada cultivar, foram estudados oito tratamentos (arranjos de plantas), obtidos pela combinação de dois espaçamentos entre fileiras $(0,45 \mathrm{~m}$ e $0,90 \mathrm{~m})$ e quatro populações iniciais de plantas (25.000 plantas ha-1, 40.000 plantas ha ${ }^{-1}$, 55.000 plantas ha $^{-1}$ e 70.000 plantas ha-1) (Tabela 1). Cada unidade experimental foi constituída por 10 e 6 fileiras, nos espaçamentos de $0,45 \mathrm{~m}$ e $0,90 \mathrm{~m}$, respectivamente, e 5,0 $\mathrm{m}$ de comprimento.

A cultivar IAC 2028, desenvolvida no Programa de Melhoramento do Instituto Agronômico de Campinas, apresenta porte baixo $(150-180 \mathrm{~cm})$, frutos indeiscentes, moderada susceptibilidade a doenças, em especial ao mofo cinzento, doença causada pelo fungo Botryotinia ricini (Goldf.) Wet, teor de óleo em torno de $47 \%$ e ciclo precoce, variável de 150 a 180 dias (Savy Filho et al. 2007). A cultivar FCA-PB, desenvolvida no Programa de Melhoramento da Faculdade de Ciências Agronômicas da Universidade Estadual Paulista (Unesp), apresenta porte baixo (140$180 \mathrm{~cm}$ ), frutos indeiscentes, susceptibilidade ao mofo cinzento, teor de óleo acima de $47 \%$ e ciclo precoce, variando de 130 a 150 dias. A descrição do sistema de cultivo foi feita de acordo com Cézar et al. (1991).

Nos dias 31/10/2007 e 08/11/2008, foram realizadas as dessecações das plantas presentes nas áreas experimentais, já que se adotou o sistema plantio direto, com a utilização do herbicida glyphosate, na dose de $1.440 \mathrm{~g} \mathrm{ha}^{-1}$ do ingrediente ativo (i.a.), utilizando-se volume de aplicação de $200 \mathrm{~L} \mathrm{ha}^{-1}$. Estas aplicações foram realizadas com pulverizador tratorizado, com barras de $12,0 \mathrm{~m}$ de comprimento e bicos leque 110,02 espaçados em 0,50 m.

A abertura dos sulcos e distribuição do adubo foram realizadas com uma semeadora-adubadeira

Tabela 1. Descrição dos tratamentos.

\begin{tabular}{cccc}
\hline \multirow{2}{*}{ Tratamento } & $\begin{array}{c}\text { População de } \\
\text { plantas }\end{array}$ & $\begin{array}{c}\text { Espaçamento } \\
\text { entre fileiras }\end{array}$ & $\begin{array}{c}\text { Distância entre } \\
\text { plantas na fileira }\end{array}$ \\
\cline { 2 - 4 } plantas ha $^{-1}$ & \multicolumn{2}{c}{$\mathrm{m}$} & \\
\hline T1 & 25.000 & 0,45 & 0,89 \\
T2 & 40.000 & 0,45 & 0,56 \\
T3 & 55.000 & 0,45 & 0,40 \\
T4 & 70.000 & 0,45 & 0,32 \\
T5 & 25.000 & 0,90 & 0,44 \\
T6 & 40.000 & 0,90 & 0,28 \\
T7 & 55.000 & 0,90 & 0,20 \\
T8 & 70.000 & 0,90 & 0,16 \\
\hline
\end{tabular}


tratorizada, modelo Personale DRILL-13, marca Semeato, regulada de acordo com o espaçamento, adotando-se o sistema plantio direto. A adubação de semeadura constou da aplicação, nos dois anos e em todos os tratamentos, de $150 \mathrm{~kg} \mathrm{ha}^{-1}$ da fórmula 08-28-16, seguindo-se recomendações de Savy Filho (1996).

Na semeadura, colocaram-se, nos sulcos, as quantidades de sementes necessárias para a obtenção do dobro das populações de plantas desejadas para cada tratamento, nos dias 09/11/2007 e 21/11/2008. As sementes foram tratadas com o fungicida carboxin + tiram $\left(60+60\right.$ g do i.a. $100 \mathrm{~kg}^{-1}$ de sementes $)$ e com o inseticida tiametoxam (140 g do i.a. $100 \mathrm{~kg}^{-1}$ de sementes). As emergências de ambas as cultivares ocorreram em 21/11/2007 e 03/12/2008. Aos 10 DAE, foram realizados desbastes, deixando-se a população de plantas planejada para cada tratamento. A adubação de cobertura consistiu da aplicação de $60 \mathrm{~kg} \mathrm{ha}^{-1}$ de N, na forma de sulfato de amônio, em 21/12/2007 e 02/01/2009, ou seja, aos 30 DAE.

Durante todo o período de desenvolvimento da mamona, foram realizadas capinas manuais, para o controle das plantas daninhas que surgiram na área. O controle preventivo do mofo cinzento foi realizado mediante aplicações dos fungicidas iprodiona (500 g do i.a. ha ${ }^{-1}$ ), no dia 21/12/2007; procimidona (500 g do i.a. ha-1), nos dias 09/01/2008, 21/01/2009 e 20/02/2009; procimidona (500 g do i.a. ha ${ }^{-1}$ ) e epoxiconazol + piraclostrobina $\left(20+53,2 \mathrm{~g}\right.$ do i.a. $\left.\mathrm{ha}^{-1}\right)$, no dia 31/02/2008.

As colheitas foram realizadas nos dias $18 / 04 / 2008$ e 20/04/2009 (FCA-PB) e nos dias 26/04/2008 e 30/04/2009 (IAC 2028), manualmente.

O cálculo do custo de produção foi baseado na metodologia proposta por Matsunaga et al. (1976), segundo a qual o Custo Operacional Total (COT) é composto das despesas com operações mecanizadas, operações manuais e material consumido. Faz parte do COT, além do Custo Operacional Efetivo (COE), outras despesas e juros de custeio. Os itens que compuseram o COT foram os seguintes:

a) Operações mecanizadas: tempo necessário de máquinas e implementos/equipamentos, para a realização de cada operação, definindo-se, neste caso, os coeficientes técnicos, em termos de hora máquina (HM), incluindo despesas com combustíveis, lubrificantes, tratorista, reparos e manutenção, dentre outras;

b) Operações manuais: foi realizado um levantamento das necessidades de mão de obra, nas diversas fases do ciclo produtivo, relacionando-se, para cada operação realizada, o número de homens/ dia (HD) para executá-la. Em seguida, os coeficientes técnicos de mão de obra foram multiplicados pelo valor médio da região, para mão de obra comum;

c) Materiais: os preços foram os vigentes no período de coleta de dados (2010), multiplicados pelas quantidades de materiais utilizados;

d) Outras despesas: considerou-se 5\% das despesas variáveis, isto é, com operações mecanizadas, operações manuais e materiais (COE), segundo Martin et al. (1997);

e) Juros de custeio: foi considerada taxa de $8,75 \%$ a.a. sobre o valor médio das despesas variáveis.

Para determinar a lucratividade da cultura da mamona, foram calculados, segundo Martin et al. (1997), a receita bruta (RB), como o produto da quantidade produzida pelo preço médio de venda; o lucro operacional (LO), como a diferença entre a receita bruta e o custo operacional total; e o índice de lucratividade (IL), entendido como sendo igual à proporção da receita bruta que se constitui em recursos disponíveis, após a cobertura do COT.

Foi considerado o preço médio recebido pelo produtor do município de Botucatu, em abril de 2010, de $\mathrm{R} \$ 0,80 \mathrm{~kg}^{-1}$ de mamona, valor que, nos últimos anos, no Estado de São Paulo, vem sofrendo redução, pois, em 2007, o preço médio era de $\mathrm{R} \$ 1,31 \mathrm{~kg}^{-1}$, em 2008 de R $\$ 0,92 \mathrm{~kg}^{-1} \mathrm{e}$, em 2009, de R $\$ 0,75 \mathrm{~kg}^{-1}$ (IEA 2010).

Os dados necessários à realização do trabalho, considerando-se os aspectos ligados à tecnologia e produção, foram obtidos de 2007 a 2010, mediante entrevistas e acompanhamento realizado diretamente no campo, com técnicos da região e órgãos de pesquisa, utilizando-se planilhas, com a finalidade de levantar as questões mais ligadas à tecnologia de produção. Os preços dos insumos (material), operações manuais e operações mecanizadas foram coletados no município de Botucatu, em abril de 2010, com empresas de revenda de insumos ligadas à área, técnicos da Casa da Agricultura e prefeitura, além de produtores rurais do município. Os preços foram apresentados em Real (R\$) e também convertidos para dólar (US\$), sendo 1 dólar $=\mathrm{R} \$ 1,75($ abril/2010).

\section{RESULTADOS E DISCUSSÃO}

Para um mesmo conjunto de coeficientes técnicos, porém, com diferentes quantidades de sementes, 
em virtude das populações de plantas, houve variação nos custos de produção (Tabela 2). Entretanto, as cultivares, dentro do mesmo ano agrícola, tiveram os mesmos custos, para cada faixa de população de plantas.

De maneira geral, o COT, nos tratamentos, não variou muito, porém, os maiores custos se deram nos tratamentos com maiores populações de plantas, já que, nestes, foram necessárias maiores quantidades de sementes (Tabelas 2 e 3). Além disto, no ano agrícola 2007/2008, o custo de produção também foi incrementado pela necessidade de duas aplicações de fungicidas a mais do que no ano agrícola 2008/2009, devido às condições climáticas mais favoráveis à ocorrência de mofo cinzento.

No ano agrícola 2007/2008, foram obtidas maiores produtividades de grãos, para ambas as cultivares, independentemente do arranjo de plantas utilizado (Tabela 3). De maneira geral, o arranjo que se destacou, para ambas as cultivares, foi a combinação do espaçamento de $0,45 \mathrm{~m}$ entre fileiras e 55.000 plantas $\mathrm{ha}^{-1}$ (T3), com valores acima de $4.500 \mathrm{~kg} \mathrm{ha}^{-1}$, no ano agrícola 2007/2008, e de $3.400 \mathrm{~kg} \mathrm{ha}^{-1}$, em 2008/2009. Contudo, os tratamentos T2 $\left(0,45 \mathrm{~m} \mathrm{x}^{-10.000}\right.$ plantas ha $\left.^{-1}\right)$ e T4 $(0,45 \mathrm{~m} \mathrm{x}$ 70.000 plantas $\left.^{-1}{ }^{-1}\right)$ também proporcionaram elevada produtividade de grãos, nos dois anos agrícolas. As produtividades obtidas foram mais elevadas que as relatadas por Savy Filho et al. (2007) e Severino et al. (2006a e 2006b), provavelmente devido aos espaçamentos entre fileiras mais estreitos e populações de plantas mais elevadas utilizados no presente trabalho.

Verificou-se que, para a cultivar IAC 2028, o lucro operacional da atividade, no ano agrícola 2007/2008, só foi negativo quando se obteve produtividade abaixo de $3.427 \mathrm{~kg} \mathrm{ha}^{-1}$ (Tabela 3 ). Considerando-se ser esta a menor produtividade, para o conjunto de fatores utilizado, torna-se, portanto, inviável produzir em patamares tão baixos. A combinação de população de plantas e espaçamento que proporcionou o melhor retorno econômico foi $0,45 \mathrm{~m} \times 70.000$ plantas (T4), com produtividade de $4.990 \mathrm{~kg} \mathrm{ha}^{-1}$, apresentando lucro operacional de R\$ 1.654,21 e índice de lucratividade de 41,44\%. Já o tratamento T5 (0,90 $\mathrm{m} \times 25.000$ plantas $)$ apresentou o menor lucro operacional (R\$-139,01), com produtividade de $3.427 \mathrm{~kg} \mathrm{ha}^{-1} \mathrm{e}$, consequentemente, índice de lucratividade negativo $(-5,07 \%)$.

Quanto à cultivar FCA-PB, no ano agrícola 2007/2008, foram observados resultados bem satisfatórios, pois todos os tratamentos apresentaram lucro operacional positivo (Tabela 3 ). O tratamento que

Tabela 2. Custos de produção para diferentes populações de plantas das cultivares de mamona IAC2028 e FCA-PB, nos anos agrícolas 2007/2008 e 2008/2009 (Botucatu, SP, abril de 2010).

\begin{tabular}{|c|c|c|c|c|c|c|c|c|}
\hline \multirow{3}{*}{ Descrição } & \multicolumn{2}{|c|}{25.000 plantas ha $^{-1}$} & \multicolumn{2}{|c|}{40.000 plantas ha $^{-1}$} & \multicolumn{2}{|c|}{55.000 plantas ha $^{-1}$} & \multicolumn{2}{|c|}{70.000 plantas ha-1 } \\
\hline & $2007 / 2008$ & $2008 / 2009$ & $2007 / 2008$ & $2008 / 2009$ & $2007 / 2008$ & $2008 / 2009$ & $2007 / 2008$ & $2008 / 2009$ \\
\hline & \multicolumn{8}{|c|}{$\mathrm{R} \$ \mathrm{ha}^{-1}$} \\
\hline \multicolumn{9}{|l|}{ A. Operações mecanizadas } \\
\hline Implantação & 84,18 & 84,18 & 84,18 & 84,18 & 84,18 & 84,18 & 84,18 & 84,18 \\
\hline Tratos culturais & 213,88 & 153,65 & 213,88 & 153,65 & 213,88 & 153,65 & 213,88 & 153,65 \\
\hline Colheita & 71,51 & 71,51 & 71,51 & 71,51 & 71,51 & 71,51 & 71,51 & 71,51 \\
\hline Subtotal A & 369,56 & 309,33 & 369,56 & 309,33 & 369,56 & 309,33 & 369,56 & 309,33 \\
\hline \multicolumn{9}{|l|}{ B. Operações manuais } \\
\hline Implantação & 17,50 & 17,50 & 17,50 & 17,50 & 17,50 & 17,50 & 17,50 & 17,50 \\
\hline Tratos Culturais & 105,00 & 105,00 & 105,00 & 105,00 & 105,00 & 105,00 & 105,00 & 105,00 \\
\hline Colheita & 367,50 & 367,50 & 367,50 & 367,50 & 367,50 & 367,50 & 367,50 & 367,50 \\
\hline Subtotal B & 490,00 & 490,00 & 490,00 & 490,00 & 490,00 & 490,00 & 490,00 & 490,00 \\
\hline \multicolumn{9}{|l|}{ C. Material } \\
\hline Fertilizantes & 386,40 & 386,40 & 386,40 & 386,40 & 386,40 & 386,40 & 386,40 & 386,40 \\
\hline Defensivos & 578,49 & 318,49 & 587,98 & 327,98 & 601,28 & 341,28 & 612,67 & 352,67 \\
\hline Sementes & 117,00 & 117,00 & 162,00 & 162,00 & 225,00 & 225,00 & 279,00 & 279,00 \\
\hline Subtotal C & $1.081,89$ & 821,89 & $1.136,38$ & 876,38 & $1.212,68$ & 952,68 & $1.278,07$ & $1.018,07$ \\
\hline Total $(\mathrm{A}+\mathrm{B}+\mathrm{C})-\mathrm{COE}$ & $1.941,45$ & $1.621,22$ & $1.995,94$ & $1.675,72$ & $2.072,24$ & $1.752,01$ & $2.137,63$ & $1.817,40$ \\
\hline Outras despesas & 97,07 & 81,06 & 99,80 & 83,79 & 103,61 & 87,60 & 106,88 & 90,87 \\
\hline Juros de custeio & 84,94 & 70,93 & 87,32 & 73,31 & 90,66 & 76,65 & 93,52 & 79,51 \\
\hline COT & $2.123,46$ & $1.773,21$ & $2.183,06$ & $1.832,82$ & $2.266,51$ & $1.916,26$ & $2.338,03$ & $1.987,79$ \\
\hline
\end{tabular}


Tabela 3. Custos, produtividade e indicadores de lucratividade da cultura da mamona ha ${ }^{-1}$, nos anos agrícolas 2007/2008 e 2008/2009 (Botucatu, SP, abril de 2010).

\begin{tabular}{|c|c|c|c|c|c|c|c|c|c|}
\hline \multirow{3}{*}{ Tratamento } & \multirow{2}{*}{ COT } & \multicolumn{2}{|c|}{ Produtividade de grãos } & \multicolumn{2}{|c|}{ Receita bruta } & \multicolumn{2}{|c|}{ Lucro operacional } & \multicolumn{2}{|c|}{ Índice de lucratividade } \\
\hline & & IAC 2028 & FCA-PB & IAC 2028 & FCA-PB & IAC 2028 & FCA-PB & IAC 2028 & FCA-PB \\
\hline & $\mathrm{R} \$$ & \multicolumn{2}{|c|}{$-\mathrm{kg} \mathrm{ha}^{-1} \longrightarrow$} & \multicolumn{4}{|c|}{$\mathrm{R} \$ \longrightarrow$} & \multicolumn{2}{|c|}{$\%$} \\
\hline & \multicolumn{9}{|c|}{ Safra $2007 / 2008$} \\
\hline $\mathrm{T} 1$ & $2.123,46$ & 3.620 & 3.796 & $2.895,76$ & $3.036,96$ & 772,30 & 913,50 & 26,67 & 30,08 \\
\hline $\mathrm{T} 2$ & $2.183,06$ & 4.353 & 5.067 & $3.482,72$ & $4.053,36$ & $1.299,66$ & $1.870,30$ & 37,32 & 46,14 \\
\hline $\mathrm{T} 3$ & $2.266,51$ & 4.577 & 5.222 & $3.661,68$ & $4.177,20$ & $1.395,17$ & $1.910,69$ & 38,10 & 45,74 \\
\hline $\mathrm{T} 4$ & $2.338,03$ & 4.990 & 5.061 & $3.992,24$ & $4.049,12$ & $1.654,21$ & $1.711,09$ & 41,44 & 42,26 \\
\hline T5 & $2.123,46$ & 3.427 & 3.961 & $2.741,52$ & $3.168,72$ & $-139,01$ & $1.045,26$ & $-5,07$ & 32,99 \\
\hline T6 & $2.183,06$ & 3.460 & 4.217 & $2.768,24$ & $3.373,20$ & 585,18 & $1.190,14$ & 21,14 & 35,28 \\
\hline $\mathrm{T} 7$ & $2.266,51$ & 4.007 & 5.009 & $3.205,52$ & $4.007,52$ & 939,01 & $1.741,01$ & 29,29 & 43,44 \\
\hline T8 & $2.338,03$ & 3.735 & 4.592 & $2.988,08$ & $3.673,44$ & 650,05 & $1.335,41$ & 21,75 & 36,35 \\
\hline & \multicolumn{9}{|c|}{ Safra 2008/2009 } \\
\hline $\mathrm{T} 1$ & $1.773,21$ & 3.188 & 2.834 & $2.550,58$ & $2.267,53$ & 777,37 & 494,32 & 30,48 & 21,80 \\
\hline $\mathrm{T} 2$ & $1.832,82$ & 3.133 & 3.374 & $2.506,44$ & $2.699,21$ & 673,63 & 866,40 & 26,88 & 32,10 \\
\hline T3 & $1.916,26$ & 4.010 & 3.451 & $3.207,65$ & $2.760,58$ & $1.291,39$ & 844,32 & 40,26 & 30,58 \\
\hline $\mathrm{T} 4$ & $1.987,79$ & 3.276 & 3.336 & $2.621,12$ & $2.668,68$ & 633,33 & 680,90 & 24,16 & 25,51 \\
\hline T5 & $1.773,21$ & 2.603 & 2.285 & $2.082,21$ & $1.828,24$ & 309,00 & 55,02 & 14,84 & 3,01 \\
\hline T6 & $1.832,82$ & 2.870 & 2.551 & $2.295,61$ & $2.040,95$ & 462,79 & 208,13 & 20,16 & 10,20 \\
\hline $\mathrm{T} 7$ & $1.916,26$ & 2.220 & 2.881 & $1.775,70$ & $2.304,81$ & $-140,56$ & 388,55 & $-7,92$ & 16,86 \\
\hline T8 & $1.987,79$ & 2.462 & 2.667 & $1.969,69$ & $2.133,38$ & $-18,10$ & 145,59 & $-0,92$ & 6,82 \\
\hline
\end{tabular}

Fonte: Dados da pesquisa (2010).

teve o melhor lucro operacional foi o T3 $(0,45 \mathrm{~m} \mathrm{x}$ 55.000 plantas), sendo de R\$ $1.910,69 \mathrm{ha}^{-1}$, com índice de lucratividade de $45,74 \%$. No entanto, o T2, mesmo apresentando o segundo maior lucro operacional (R\$ 1.870,30), obteve o maior índice de lucratividade $(46,14 \%)$, por apresentar COT um pouco menor do que o T3.

Quanto ao ano agrícola 2008/2009, o arranjo de plantas que proporcionou o melhor resultado econômico da cultivar IAC 2028 foi o T3 $\left(0,45 \mathrm{~m}\right.$ x 55.000 plantas ha $\left.^{-1}\right)$, com produtividade de $4.010 \mathrm{~kg} \mathrm{ha}^{-1}$, lucro operacional de R\$1.291,39 $\mathrm{ha}^{-1}$ e índice de lucratividade de 40,26\% (Tabela 3). Para a cultivar FCA-PB, o arranjo de plantas que proporcionou melhor retorno econômico foi de $0,45 \mathrm{~m} \mathrm{x} 40.000$ plantas ha $^{-1}$ (T2), com produtividade de $3.374 \mathrm{~kg} \mathrm{ha}^{-1}$, lucro operacional de $\mathrm{R} \$ 866,40 \mathrm{ha}^{-1}$ e índice de lucratividade de $32,10 \%$. No ano agrícola 2008/2009, a receita da melhor combinação de espaçamento entre fileiras e população de plantas da cultivar IAC 2028 (T3) foi quase 50\% superior ao maior lucro operacional obtido para a cultivar FCA-PB, muito embora representasse quase $68 \%$ do lucro obtido pela cultivar FCA-PB no tratamento T3 $(0,45 \mathrm{~m} \times 55.000$ plantas ha-1), no ano agrícola $2007 / 2008$.

O tratamento T7 (0,90 m x 55.000 plantas ha $\left.{ }^{-1}\right)$, para a cultivar IAC 2028, foi o que apresentou o menor lucro operacional ( $\left.\mathrm{R} \$-140,56 \mathrm{ha}^{-1}\right)$ e índice de lucratividade de $-7,92 \%$ (Tabela 3), valores que refletem a baixa produtividade obtida no segundo ano agrícola (2.220 kg ha-1). Já para a cultivar FCA-PB, o menor lucro operacional foi obtido no tratamento T5 $\left(0,90 \mathrm{~m} \times 25.000\right.$ plantas ha $\left.\mathrm{h}^{-1}\right)$, com R $\$ 55,02 \mathrm{ha}^{-1}$, devido à menor produtividade $\left(2.285 \mathrm{~kg} \mathrm{ha}^{-1}\right)$, que levou a um índice de lucratividade de 3,01\%.

De maneira geral, no ano agrícola 2007/2008, houve melhores resultados de lucro operacional para as duas cultivares (Tabela 3 e Figura 1). Para a cultivar IAC 2028, com exceção do tratamento T5 $(0,90 \mathrm{~m} \times 25.000$ plantas ha-1), todos os outros apresentaram resultados positivos. Já para a cultivar FCA-PB, houve lucro operacional positivo em todos os tratamentos, assim como na safra 2008/2009, em que a cultivar IAC 2028 obteve lucros operacionais negativos apenas nos tratamentos $\mathrm{T} 7 \mathrm{e}$ T8.

Nos dois anos agrícolas, quando se fez uma análise conjunta das duas cultivares, verificou-se que o menor espaçamento entre fileiras $(0,45 \mathrm{~m})$ proporcionou, de modo geral, maiores lucros operacionais do que o espaçamento mais largo $(0,90 \mathrm{~m})$, independentemente da população de plantas. Tal fato é explicado por Rocha et al. (1964), Tourinho et al. (2002) e Severino et al. (2006a), os quais concluíram que o aumento no espaçamento entre fileiras, em uma mesma população de plantas, promove o adensamento de plantas na fileira, ou seja, o aumento da população de plantas, resultando em uma compe- 


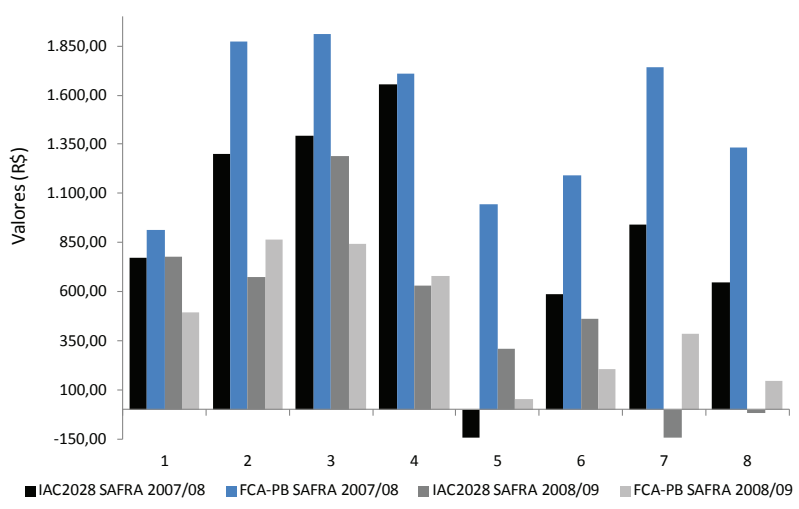

Figura 1. Lucro operacional $\left(\mathrm{R} \$ \mathrm{ha}^{-1}\right)$, em relação ao COT, para cada tratamento das cultivares de mamoneira IAC 2028 e FCA-PB, nos anos agrícolas 2007/2008 e 2008/2009 (Botucatu, SP, abril de 2010).

tição intraespecífica por nutrientes, água, luz e $\mathrm{CO}_{2}$, e consequente decréscimo de produção por planta.

\section{CONCLUSÕES}

1. Os melhores resultados econômicos foram obtidos quando se utilizou espaçamento entre fileira mais estreito $(0,45 \mathrm{~m})$, principalmente no ano agrícola 2007/2008.

2. O maior COT foi de $\mathrm{R} \$ 2.338,03 \mathrm{ha}^{-1}$ e ocorreu no ano agrícola 2007/2008, para a população de 70.000 plantas ha $^{-1}$, em função da utilização de maior quantidade de sementes para a semeadura, e, também, da necessidade de duas aplicações a mais de fungicidas do que no ano agrícola seguinte.

3. A cultivar FCA-PB apresentou os melhores índices de lucratividade, sendo o maior $(46,14 \%)$ obtido com a utilização da combinação do espaçamento entre fileiras de $0,45 \mathrm{~m}$ e 40.000 plantas ha $^{-1}$, no ano agrícola 2007/2008, com lucro operacional de $\mathrm{R} \$ 1.870,30 \mathrm{ha}^{-1}$.

\section{AGRADECIMENTOS}

À Fundação de Amparo à Pesquisa do Estado de São Paulo (FAPESP), pela concessão de bolsa de Pós-Doutorado ao primeiro autor e de Mestrado ao terceiro autor.

\section{REFERÊNCIAS}

CARVALHO, E. V. et al. Densidade de plantio em duas cultivares de mamona no sul do Tocantins. Ciência Agronômica, Fortaleza, v. 41, n. 3, p. 387-392, 2010.
CÉZAR, S. A. G. et al. Sistemas de produção dentro de uma abordagem metodológica de custos agrícolas. Agricultura em São Paulo, São Paulo, v. 38, n. 2, p. 117149, 1991.

COMPANHIA NACIONAL DE ABASTECIMENTO (Conab). Safras: série histórica (mamona). 2010. Disponível em: <http://www.conab.gov.br $>$. Acesso em: 25 ago. 2011.

EMPRESA BRASILEIRA DE PESQUISA AGROPECUÁRIA (Embrapa). Sistema brasileiro de classificação dos solos. Rio de Janeiro: Embrapa/CNPSO, 2006.

FOOD AND AGRICULTURE ORGANIZATION (FAO). Production and trade: castor beans. 2008. Disponível em: $<$ http://faostat.fao.org >. Acesso em: 31 ago. 2010.

INSTITUTO BRASILEIRO DE GEOGRAFIA E ESTATÍSTICA (IBGE). Produção agrícola municipal (PAM). 2010. Disponível em: <http://www.sidra.ibge.gov. br>. Acesso em: 31 ago. 2010.

INSTITUTO DE ECONOMIAAGRÍCOLA(IEA). Preços médios mensais recebidos pelos agricultores. 2010. Disponível em: <http://ciagri.iea.sp.gov.br/bancoiea/ precos_medios.aspx?cod_sis=2>. Acesso em: 6 abr. 2010.

MARTIN, N. B. et al. Sistema "Custagri": sistema integrado de custos agropecuários. São Paulo: IEA/SAA, 1997.

MATSUNAGA, M. et al. Metodologia de custo de produção utilizada pelo IEA. Agricultura em São Paulo, São Paulo, v. 23, n. 1, p. 123-39, 1976.

NASS, L. L.; PEREIRA, P. A. A.; ELLIS, D. Biofuels in Brazil: an overview. Crop Science, Madison, v. 47, n. 6, p. 2228-2237, 2007.

RAIJ, B. V. et al. Análise química para avaliação da fertilidade de solos tropicais. Campinas: Instituto Agronômico, 2001.

ROCHA, J. L. V. et al. Adubação da mamoneira: IV - experiências de espaçamento x adubação ( $2^{\mathrm{a}}$ série). Bragantia, Campinas, v. 23, n. 20, p. 257-269, 1964.

SANTOS, R. F. et al. Aspectos econômicos do agronegócio da mamona. In: AZEVEDO, D. M. P. de; BELTRÃO, N. E. de M. (Eds.). O agronegócio da mamona no Brasil. 2. ed. Campina Grande: Embrapa Algodão; Brasília, DF: Embrapa Informação Tecnológica, 2007. p. 21-42.

SAVY FILHO, A. Mamona. In: RAIJ, B. V. et al. Recomendações de adubação e calagem para o Estado de São Paulo. 2. ed. Campinas: Instituto Agronômico, 1996. p. 201. (Boletim técnico, 100). 
SAVY FILHO, A.; BANZATTO, N. V. Mamona (Ricinus communis L.). In: JORGE, J. A.; LOURENÇÃO, A. L.; ARANHA, C. Instruções agrícolas para o Estado de são Paulo. 5. ed. Campinas: Instituto Agronômico, 1990. p. 132-133. (Boletim técnico, 200).

SAVY FILHO, A. et al. IAC-2028: nova cultivar de mamona. Pesquisa Agropecuária Brasileira, Brasília, DF, v. 42, n. 3, p. 449-452, 2007.

SAVY FILHO, A. et al. Mamona: In: COORDENADORIA DE ASSISTÊNCIA TÉCNICA INTEGRAL. Oleaginosas no Estado de São Paulo: análise e diagnóstico. Campinas: CATI, 1999. p. 29-39. (Documento técnico, 107).

SEVERINO, L. S. et al. Otimização do espaçamento de plantio para a mamoneira cultivar BRS Nordestina. Revista Brasileira de Oleaginosas e Fibrosas, Campina Grande, v. 10, n. 1/2, p. 993-999, 2006a.
SEVERINO, L. S. et al. Crescimento e produtividade da mamoneira influenciada por plantio em diferentes espaçamentos entre linhas. Ciência Agronômica, Fortaleza, v. 37 , n. 1 , p. $50-54,2006$ b.

TOURINHO, M. C. C.; REZENDE, P. M.; SALVADOR, $\mathrm{N}$. Espaçamento, densidade e uniformidade de semeadura na produtividade e características agronômicas da soja. Pesquisa Agropecuária Brasileira, Brasília, DF, v. 37, n. 8, p. 1071-1077, 2002. 